\title{
BRAZIL LOOKING FOR COMPLETING HIS SPACE IN BARIATRIC SURGERY
}

\author{
O Brasil procurando preencher o seu espaço na cirurgia bariátrica
}

\author{
Almino C. RAMOS
}

Presidente da Sociedade Brasileira de Cirurgia Bariátrica e Metabólica - SBCBM

W hen the end of this mandate front SBCBM is approaching, it is appropriate to report the key facts that characterized our activities. They were many and in various directions. It is a pride for all us to recognize that Brazil has a society of bariatric surgery strong and respected throughout the world, conceived with hard work during its existence. This credit can be measured by the growing interest in bariatric surgery in Brazil and by increasing our representation in world events. In all congresses on bariatric and metabolic surgery of international relevance, we have Brazilian surgeons participating as speakers. We also have the second most important congress of bariatric surgery in the world, with more than 1200 participants. In the world congresses in the area, Brazilians represent the second or third delegation and today we have two members on the executive board of "The International Federation for the Surgery of Obesity and Metabolic Disorders (IFSO)".

In these two years, SBCBM acted strongly with the press and other specialties showing that obesity must be considered as a disease that requires specialized treatment, and not only as an aesthetic problem. We emphasized that, more than weight loss, the control of comorbidities - often associated -, can improve the quality of life with great health benefit. This awareness, coupled with the great improvement of the results of bariatric and metabolic surgery, contributed to the increasing number of bariatric surgeries in Brazil, which was 72000 operations last year and 2014 signalize to have more than 80000 operated patients. This is the second highest number of operations in the world, behind only USA with about 140000 . This fact alone would justify the existence of our society. In addition, there is persistent search for skills improvement among our members. We also did public awareness regarding the risks and benefits of bariatric procedures, seeking to repress the panacea that runs on people minds, considering bariatric surgery as a simple and easy alternative solution for weight loss without sacrifice. The goal has always been clear that the method should be understood as a multidisciplinary program with previous preparation, surgery and postoperative follow-up.

As reflex of the intense activities - always aiming scientific and professional enhancement - this mandate increased in $36 \%$ the number of Society members; firstly when we assume was 1,012 and now 1,390. This growth was not only in number but also in quality; in the period we had marked increase in Full Members, adding new 81 names: 41 in 2013 and 40 in 2014. Decentralization to reach the most remote corners of our vast country, was stimulated by the creation of 15 chapters spread throughout Brazil.

Not satisfied in having less than $10 \%$ of Brazilian bariatric operations done in public hospitals, remarkable activity was carried out stimulating the Federal Government through SUS (Unified Brazilian Health System) looking for the increase of bariatric surgery in Brazil, done by public assistance. With the effort to universalize the procedures, the Society helped the government to increase to $20 \%$ the number of operations performed by SUS; various training courses with multidisciplinary teams were done to meet this goal. The implementation of laparoscopy in bariatric surgery in public hospitals was also targeted in several meetings, and may be a reality very soon.

In order to work with multidisciplinary and promote continuing education, current management courses were held together with correlated medical associations: Brazilian Society of Endocrinology and Metabolism - SBEM, Brazilian Diabetes Society - SBD, Brazilian Association for the Study of Obesity and Metabolic Syndrome - ABESO, Brazilian College of Surgeons - CBC and Brazilian College of Digestive Surgery - CBCD. Conducting several associated events, all these interactions were directed, among others, for greater inter-societal exchange, and, also, for define and formalize parameters to better indicate metabolic surgery in Brazil.

It is with pride that we increased the interest of our community for research in Brazil's bariatric area. Over the past few years there has been significant increase in the number of papers executed by our community. Due to scientific association that exists with the Brazilian Archives of Digestive Surgery - $A B C D$, we could provide international vehicle for scientific communication to our members. With international visibility accessed through the web media, ABCD permitted that the greater part of Brazilian bariatric scientific production in the period had the chance to be globally and immediately seen through the most important international scientific bases: Medline/PubMed and SciELO. Full papers increased up $20 \%$ since the moment when SBCBM, along with $A B C D$, started publishing special supplements to be distributed in SBCBM congresses, exalting that all these papers will be permanently available, in bilingual form, on these bases. Also another supplement - this one only with summaries of free communications, free videos and posters - is in its fifth edition with measurable increase year by year. This year we had a record number of 270 papers submitted by bariatric community throughout Brazil. It is a success and joy in seeing how the SBCBM has contributed to this enhancement.

This Congress in Rio will have a record number of participants and here, with great satisfaction and a sense of accomplished mission, we will begin the final step of our mandate. At this moment it is necessary to say that all we got was with the commitment of our entire board of directors, the board of the chapters and the excitement of the permanent members, who encouraged us to achieve so much expressive multifocal production of a scientific society in so short management time.

Let's continue, always improving what we have done, because the future awaits us with new innovations and challenges. We are winners and the best answer we can give to our country is that: WE DID OUR PART! and SBCBM will continue doing so. 